\title{
Curative efficacy might be an early predictor of prognosis in patients with small cell lung cancer treated with 2 cycles of platinum-based first-line chemotherapy
}

\author{
Kaibo Zhu ${ }^{1 \#}$, Minlin Jiang ${ }^{2,3 \#}$, Yi Xu ${ }^{2,3 \#}$, Peixin Chen ${ }^{2,3}$, Hao Wang ${ }^{2,3}$, Jia Yu$^{2,3}$, Jun Zhu ${ }^{2,3}$, \\ Wencheng Zhao ${ }^{2,3}$, Die Meng ${ }^{2,3}$, Yayi He ${ }^{1}$ \\ ${ }^{1}$ Department of Hematology, Xiangtan Central Hospital, Xiangtan, China; ${ }^{2}$ Department of Medical Oncology, Shanghai Pulmonary Hospital, Tongji \\ University Medical School Cancer Institute, Tongji University School of Medicine, Shanghai, China; ${ }^{3}$ Tongji University, Shanghai, China \\ Contributions: (I) Conception and design: K Zhu, M Jiang, Y Xu, D Meng, Y He; (II) Administrative support: D Meng, Y He; (III) Provision of study \\ materials or patients: Y He; (IV) Collection and assembly of data: K Zhu, M Jiang, Y Xu, P Chen, J Yu, J Zhu; (V) Data analysis and interpretation: K \\ Zhu, M Jiang, Y Xu, W Zhao, H Wang; (VI) Manuscript writing: All authors; (VII) Final approval of manuscript: All authors. \\ \#These authors contributed equally to this work. \\ Correspondence to: Die Meng. Department of Medical Oncology, Shanghai Pulmonary Hospital, Tongji University Medical School Cancer Institute, \\ Tongji University School of Medicine, No 507 Zhengmin Road, Shanghai 200433, China. Email: mandymengsh@126.com; Yayi He. Department of \\ Hematology, Xiangtan Central Hospital, Xiangtan 411100, China. Email: 2250601@qq.com.
}

Background: Platinum-based chemotherapy remains the essential therapy for small cell lung cancer (SCLC). Here, we conducted a statistical analysis to explore whether the curative efficacy of 2-cycle platinum-based chemotherapy can predict the survival of patients with SCLC.

Methods: Fifty-six SCLC patients who had each received 2 cycles of platinum-based chemotherapy were enrolled. The curative efficacy of the chemotherapy was evaluated, mainly by chest computed tomography, and the treatment response was categorized according to the Response Evaluation Criteria in Solid Tumors (RECIST) 1.1. Patients were continuously followed up for progression-free survival (PFS) and overall survival. The 55 patients were separated into 2 groups by the curative efficacy of the 2-cycle first-line platinum-based chemotherapy. All statistical analyses were performed with SPSS software (version 17.0; SPSS, Inc.; Chicago, IL, USA)

Results: Patients who responded to 2-cycle chemotherapy (partial response, PR) had significantly better survival than others who did not (stable disease, SD or progressive disease, $\mathrm{PD}$ ). The median progressionfree survival (mPFS) in the PR group was 6.330 months, which was significantly longer than the 2.870 months seen in SD+PD group (95\% CI: 4.631-8.029 vs. 0.000-5.790, $\mathrm{P}=0.022$ ). The median overall survival (mOS) was 10.870 months in the PR group, which was remarkably longer than the 8.970 months observed in the SD+PD group (95\% CI: 9.546-12.194 vs. 6.517-11.423, $\mathrm{P}=0.028$ ). Curative efficacy had no correlation with clinical features.

Conclusions: The curative efficacy of 2-cycle first-line platinum-based chemotherapy was significantly correlated with PFS and OS, and showed prognostic value in SCLC patients. Patients who were sensitive to chemotherapy had superior survival to those who were chemotherapy insensitive.

Keywords: Small cell lung cancer (SCLC); survival analysis; chemotherapy

Submitted Jan 21, 2021. Accepted for publication Feb 10, 2021.

doi: $10.21037 /$ jtd-21-216

View this article at: http://dx.doi.org/10.21037/jtd-21-216 


\section{Introduction}

Lung cancer is a serious, life-threatening disease that is increasing in incidence around the world $(1,2)$. Approximately $10-15 \%$ of lung cancers are categorized as small cell lung cancer (SCLC) (3-5), which is a poorly differentiated malignant epithelial tumor of neuroendocrine origin characterized by a rapid doubling time and high growth fraction, as well as high genomic instability relative to most other cancers (6-9). Data show that the majority of patients with SCLC suffer later stages, with the proportion of patients with extensive-disease SCLC (ED-SCLC) being approximately $60-75 \%(10,11)$.

A large accumulation of clinical research has evidenced the poor prognosis of SCLC patients. Untreated, the disease progresses rapidly and the median overall survival (mOS) is a meager 2-4 months from diagnosis (12). Even in the receipt of regular therapy, patients with SCLC are unable to obtain prolonged survival, with the mOS of limited-stage disease and ED reaching only 15-20 and $8-13$ months, respectively (12). In the vast majority of cases, SCLCs recur within 6 months after the completion of primary therapy (13). Unfortunately, the situation has not shown any remarkable improvement over the past few decades, and survival rate is still only $6 \%$ after 5 years (14).

Many SCLCs are sensitive to chemotherapy, with an initial response rate of up to $70 \%$ (15); thus, chemotherapy is applied as the standard first-line treatment for the disease $(8,16)$. Etoposide combined with cisplatin (EC) or carboplatin (EP) is the most commonly recommended strategy $(8,16)$, and has been proved more effective than other combinations $(17,18)$. Especially for ED-SCLC, the first-line therapeutic choice is 4 to 6 cycles of EC or EP (19). Great efforts been made to advance therapeutic strategies for SCLC. Immunotherapy, for instance, is a cutting-edge treatment that can prolong the survival of patients; however, this survival extension is limited to only approximately 2 months (20-22). Therefore, platinum-based chemotherapy has remained the cornerstone of standard first-line treatment for decades, and the current lack of other agents approved as being significantly efficacious needs to be acknowledged (23).

Indeed, platinum-based chemotherapy can achieve a favorable response and rapid improvement in most patients with SCLC; however, its effects are not long-lasting and patient outcomes are still unsatisfactory. Moreover, 30-40\% of SCLC patients are resistant to chemotherapy (14). Therefore, whether or not the response to first-line therapy is correlated with patient outcomes and can serve as a prognostic factor demands exploration. Here, we enrolled SCLC patients who had received only EC or EP therapy after diagnosis and explored whether the curative efficacy of 2-cycle first-line platinum-based chemotherapy could predict survival in SCLC. Different from the previous studies reporting relevant efficacy and adverse reaction of first-line chemotherapy on SCLC $(24,25)$, our study mainly demonstrated the clinically prognostic value of the 2 cycles of platinum-based first-line chemotherapy on SCLC prognosis. We found that the curative efficacy of 2-cycle first-line platinum-based chemotherapy was significantly correlated with progression-free survival (PFS) and overall survival (OS) in SCLC patients. Patients who were sensitive to chemotherapy had superior survival to those who were chemotherapy insensitive. These findings will benefit many SCLC patients given the important role of chemotherapy in SCLC. We present the following article in accordance with the STROBE reporting checklist (available at http://dx.doi. org/10.21037/jtd-21-216).

\section{Methods}

\section{Patients}

Fifty-six patients aged $42-82$ years who were diagnosed as SCLC in Shanghai Pulmonary Hospital from June 2018 to July 2019 were enrolled, with a median follow-up time of 13.230 months, 95\% CI: 8.981-17.479 (Figure 1). All patients received first-line platinum-based chemotherapy, which commenced no later than 1 month after diagnosis. Clinical characteristics included age, sex, smoking status, cancer stage, and chemotherapy regimens. The tumors were staged using the International Association for the Study of Lung Cancer Staging and Prognostic Factors Committee (IASLC) TNM staging system ( $8^{\text {th }}$ edition) and the Veterans Administration Lung Study Group (VALSG) system. A non-smoker was defined as a person who had smoked fewer than 100 cigarettes in their lifetime. PFS referred to the time from the date of diagnosis to the objectively recorded date of tumor progression or death. Overall survival (OS) referred to the time from the date of diagnosis to the date of death. The last date of follow up was August 23, 2020. All participants were competent to provide consent. Approval of this study was obtained from the ethics committee of Shanghai Pulmonary Hospital (ethics number: K20-022). All procedures performed in this study involving human participants were in accordance with the Declaration of 


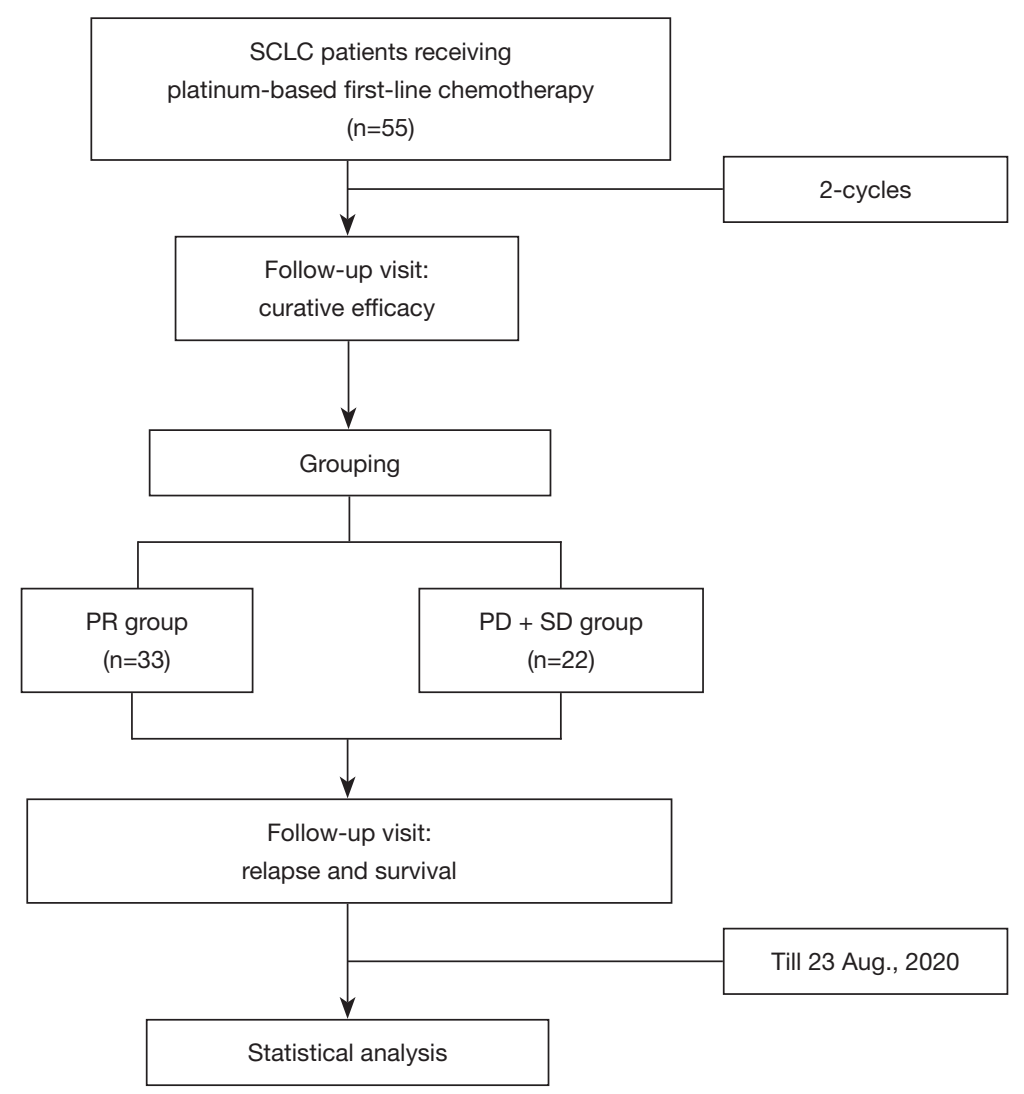

Figure 1 Study flowchart of patient enrolled.

Helsinki (as revised in 2013).

\section{Evaluation of curative efficacy and patient grouping}

"Curative efficacy" refers to the curative efficacy of 2-cycle platinum-based chemotherapy. Curative efficacy was mainly evaluated by chest computed tomography (CT). Response to chemotherapy was categorized by the Response Evaluation Criteria in Solid Tumors (RECIST 1.1) as complete response (CR), partial response (PR), stable disease (SD), or progressive disease (PD) (26). Patients were separated into 2 groups according to the curative effect. The first group (PR group, $\mathrm{N}=33$ ), the chemotherapy sensitivity group, included patients evaluated as PR. The other group (SD+PD group, $\mathrm{N}=22$ ), comprising chemotherapy-insensitive patients, included those with SD or PD.

\section{Statistical analysis}

All statistical analyses were performed with SPSS software (version 17.0; SPSS, Inc.; Chicago, IL, USA). Spearman's rank correlation was applied to examine the relationship of curative efficacy with patient clinical characteristics, while the $\chi^{2}$ test was used for the correlation analysis of curative efficacy and relapse and death. Survival analyses were conducted using the Kaplan-Meier method. To analyze the correlations of clinical features and curative efficacy with PFS and OS, Cox regression was performed. All statistics were 2-sided, with statistical significance being defined as $\mathrm{P}<0.05$.

\section{Results}

\section{Patient characteristics}

Among the 55 patients were 6 (10.9\%) females and 49 $(89.1 \%)$ males. Twenty-three $(41.8 \%)$ of the patients were non-smokers. One (1.8\%) patient had stage II, 25 (45.5\%) patients had stage III, and $30(52.7 \%)$ patients had stage IV disease. Forty $(72.7 \%)$ and $15(27.3 \%)$ patients were $<70$ and $\geq 70$, respectively (Table 1). 
Table 1 Characteristics of the 55 patients and their relationship with sensitivity to chemotherapy

\begin{tabular}{lccc}
\hline Items & Total & Chemotherapy-sensitive & Chemotherapy-insensitive \\
\hline Sex, n (\%) & & & P value \\
Male & $49(89.1 \%)$ & $28(57.1 \%)$ & $21(42.9 \%)$ \\
Female & $6(10.9 \%)$ & $5(83.3 \%)$ & $1(16.7 \%)$ \\
Age, median & 66 & $21(52.5 \%)$ & $19(47.5 \%)$ \\
$<70$ & $40(72.7 \%)$ & $12(80.0 \%)$ & $3(20.0 \%)$ \\
$\geq 70$ & $15(27.3 \%)$ & & 0.064 \\
Smoking status, $\mathrm{n}(\%)$ & & $18(78.3 \%)$ & $5(21.7 \%)$ \\
Non-smoker & $23(41.8 \%)$ & $15(46.9 \%)$ & $17(53.1 \%)$ \\
Smoker & $32(58.2 \%)$ & & 6.019 \\
Cancer staging, $\mathrm{n}(\%)$ & $20(76.9 \%)$ & $16(55.2 \%)$ \\
II-III & $26(47.3 \%)$ & $13(44.8 \%)$ & $1 \%)$ \\
IV & $29(52.7 \%)$ & & 0.015 \\
\hline
\end{tabular}
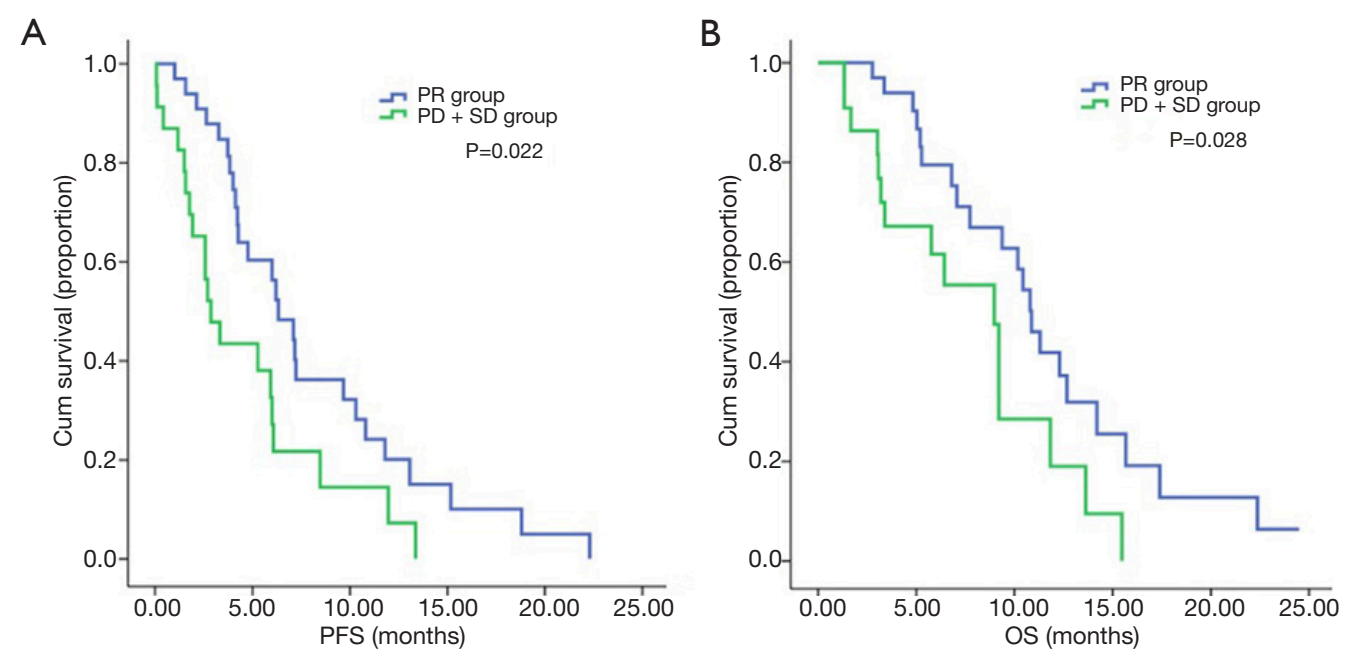

Figure 2 PFS and OS of SCLC patients by curative effect. (A) PFS between PR group and SD+PD group. (B) OS between PR group and SD+PD group. OS, overall survival; PFS, progression-free survival; PD, progressive disease; PR, partial response; SCLC, small cell lung cancer; $\mathrm{SD}$, stable disease.

\section{Correlations of curative efficacy with clinical features}

As revealed in Table 1, the clinical characteristics including sex and age of patients had no significant influence on curative efficacy $(\mathrm{P}$ values for sex and age were 0.216 and 0.064 , respectively). Besides, we detected that the curative efficacy of patients was closely correlated with smoking status and clinical staging in SCLC (P values for smoking status and stage were 0.019 and 0.015 , respectively).

\section{Curative efficacy was correlated with PFS and OS}

In the PR group enrolled patients who displayed a better curative response, the median PFS was 6.330 months, which was significantly longer than the 2.870 months observed in chemotherapy-insensitive SD+PD group (95\% CI: 4.6318.029 vs. $0.000-5.790, \mathrm{P}=0.022$ ) (Figure $2 A$ ). Furthermore, the PR group also displayed a remarkably longer median OS than SD+PD group (10.870 vs. 8.970 months; 95\% CI: 
Table 2 COX regression analysis of PFS

\begin{tabular}{|c|c|c|c|c|c|c|c|c|}
\hline \multirow{3}{*}{ Variables } & \multicolumn{4}{|c|}{ Univariate analysis } & \multicolumn{4}{|c|}{ Multivariate analysis } \\
\hline & \multirow{2}{*}{$\mathrm{HR}$} & \multicolumn{2}{|c|}{$95 \% \mathrm{Cl}$} & \multirow{2}{*}{$P$ value } & \multirow{2}{*}{$\mathrm{HR}$} & \multicolumn{2}{|c|}{$95 \% \mathrm{Cl}$} & \multirow{2}{*}{$P$ value } \\
\hline & & Down & Up & & & Down & Up & \\
\hline Sex (male vs. female) & 0.769 & 0.297 & 1.992 & 0.589 & & & & \\
\hline Age (<70 vs. $\geq 70)$ & 1.085 & 0.555 & 2.120 & 0.812 & & & & \\
\hline Cancer stage (II-III vs. IV) & 0.564 & 0.300 & 1.062 & 0.076 & & & & \\
\hline $\begin{array}{l}\text { Curative efficacy (PR vs. } \\
\text { SD+PD) }\end{array}$ & 0.496 & 0.269 & 0.915 & 0.025 & 0.496 & 0.269 & 0.915 & 0.025 \\
\hline
\end{tabular}

EC, etoposide/cisplatin; EP, etoposide/carboplatin; HR, hazard rate; PFS, progression-free survival; PD, progressive disease; PR, partial response; SD, stable disease; $95 \% \mathrm{Cl}, 95 \%$ confidence interval.

Table 3 COX regression analysis of OS

\begin{tabular}{|c|c|c|c|c|c|c|c|c|}
\hline \multirow{3}{*}{ Variables } & \multicolumn{4}{|c|}{ Univariate analysis } & \multicolumn{4}{|c|}{ Multivariate analysis } \\
\hline & \multirow{2}{*}{$\mathrm{HR}$} & \multicolumn{2}{|c|}{$95 \% \mathrm{Cl}$} & \multirow{2}{*}{$P$ value } & \multirow[t]{2}{*}{$\mathrm{HR}$} & \multicolumn{2}{|c|}{$95 \% \mathrm{Cl}$} & \multirow{2}{*}{$P$ value } \\
\hline & & Down & Up & & & Down & Up & \\
\hline Sex (male vs. female) & 0.429 & 0.160 & 1.147 & 0.092 & & & & \\
\hline Age (<70 vs. $\geq 70)$ & 0.739 & 0.365 & 1.495 & 0.400 & & & & \\
\hline Cancer stage (II-III vs. IV) & 0.657 & 0.322 & 1.342 & 0.249 & & & & \\
\hline $\begin{array}{l}\text { Curative efficacy (PR vs. } \\
\text { SD+PD) }\end{array}$ & 0.465 & 0.232 & 0.935 & 0.032 & 0.465 & 0.232 & 0.935 & 0.032 \\
\hline
\end{tabular}

EC, etoposide/cisplatin; EP, etoposide/carboplatin; HR, hazard rate; OS, overall survival; PD, progressive disease; PR, partial response;

SD, stable disease; $95 \% \mathrm{Cl}, 95 \%$ confidence interval.

9.546-12.194 vs. 6.517-11.423, $\mathrm{P}=0.028)$ (Figure $2 B)$.

\section{Univariate and multivariate analysis}

The Cox regression analysis revealed that only curative efficacy was able to predict $\mathrm{PFS}(\mathrm{P}=0.025$, hazard rate $=0.496,95 \%$ CI: $0.269-0.915)$ and $\mathrm{OS}(\mathrm{P}=0.032$, hazard rate $=0.465,95 \%$ CI: $0.232-0.935)$. Meanwhile, clinical features had no correlation with PFS or OS (Tables 2 and 3).

\section{Discussion}

In our study, we found that the curative efficacy of 2-cycle first-line platinum-based chemotherapy was significantly correlated with PFS and OS in SCLC patients, which showed the prognostic value of 2-cycle first-line platinumbased chemotherapy in SCLC. Patients who were sensitive to chemotherapy had superior survival to those who were chemotherapy insensitive. The prognosis of patients with SCLC is known to be poor (13). A number of analyses have been performed in an effort to identify prognostic factors in SCLC; so far, advanced tumor stage, high lactate dehydrogenase, low serum albumin, elevated alkaline phosphatase, low sodium, high aspartate aminotransferase, and decreased bicarbonate have been proven as effective predictors $(27,28)$. In addition, a 2018 study suggested that being overweight prior to treatment is associated with better survival and might be a predictor of OS in SCLC (29). Another analysis of 21 trials published from 1984 to 2001 indicated that patients with sensitivity to first-line 
chemotherapy had a significantly higher response rate to second-line treatment $(27.7 \%$ vs. $14.8 \%)$, as well as improved mOS (7.7 vs. 5.4 months), in comparison to chemotherapy-insensitive patients with refractory disease (30). As for genomic alterations, MYC amplification was reported correlated with poor survival in SCLC patients (31). Moreover, many immune biomarkers such as PD-1, PDL1, CD39 were investigated for predicting SCLC prognosis $(32,33)$. For relapsed SCLC, in a relapsed elderly population receiving second-line chemotherapy, a retrospective study showed that patients with good performance status and an early SCLC staging when starting first-line chemotherapy might associate with longer OS (34). These patients might also experience a longer interval between the start of the first-line treatment and that of the second-line therapy.

In the past few decades, great efforts have been made to develop novel therapeutic strategies to improve the prognosis of SCLC. Regrettably, the last drug approved for the treatment of SCLC was topotecan in 1998 (35), and currently, there are few agents that can outperform classical ones (23). Platinum-based compounds mainly target DNA, limiting the unwinding of DNA and thereby, inhibiting DNA replication, mainly in the G2 phase of mitosis $(36,37)$. SCLC proliferates faster than normal cells with rapid DNA synthesis and has an imperfect repair function for damaged DNA. Therefore, they are more sensitive to the cytotoxic effects of platinum drugs than normal cells. The significant effect of chemotherapy in SCLC was first reported as early as 1969 (38), and the advances of combination chemotherapy have been described in several studies since $(39,40)$. From a theoretical standpoint, combining agents can maximize the tumor cell-killing effect and the elimination of resistant cell lines, resulting in prolonged survival (41). Compared to those treated with etoposide monotherapy, patients who received combined agents were found to have a higher response rate and longer mOS (40). According to multiple studies, many SCLCs are highly sensitive to platinum/etoposide, with response rates ranging from $44 \%$ to $78 \%$ and notable clinical improvement (14). Therefore, despite a lack of significant improvement, combination chemotherapy remains essential to SCLC treatment (23). As recommended by National Comprehensive Cancer Network (NCCN) and European Society for Medical Oncology (ESMO) guidelines, platinum-based chemotherapy has been the standard firstline treatment of SCLC for over 20 years $(8,16)$.

The classical therapeutic strategy for SCLC consists of EC or EP, which were demonstrated to be better than other drugs by 2 meta-analyses and a phase III clinical trial $(17,18,42)$. For ED-SCLC, 4 to 6 cycles of EC or EP is the first-line treatment (43). For limited-stage SCLC, the application of platinum-based therapy is also universally recommended after surgical resection (43), and its prognosis-improving effect was evidenced in a retrospective review by Johns Hopkins University in 2005 (44).

As for the curative efficacy of cisplatin- and carboplatinbased regimens, several trials have compared the differences between them. One meta-analysis indicated that patients who received cisplatin-based therapy were more likely to have an elevated response rate compared to patients not treated with cisplatin (18). However, another meta-analysis suggested that cisplatin- and carboplatin-based therapy had no significance in terms of the response rate, PFS, or OS (19). Several studies have compared the efficacy and safety results of different platinum-based regimens combined with etoposide in the treatment of extensivestage small cell lung cancer. For example, a study in elderly ED-SCLC population demonstrated that initial therapy of carboplatin/etoposide showed similar survival and relatively less subsequent health care use compared with cisplatin/ etoposide (45). Another report analyzed the similar shortterm efficacy of etoposide in combination with lobaplatin or cisplatin in ED-SCLC patients. Except for shortterm efficacy, equivalent results were also observed when comparing OS and PFS between the two therapies. Both treatments demonstrated tolerated adverse reactions (46). Therefore, either carboplatin or cisplatin can be applied as a cornerstone of first-line treatment for SCLC. As for the toxicity of carboplatin, etoposide, and cisplatin as initial therapy for ED-SCLC, hematological toxicities such as neutropenia, thrombocytopenia, and febrile neutropenia as well as nonhematological toxicities such as electrolyte and gastrointestinal changes were the most common (47-49).

Some other drugs are also recommended as first-line chemotherapy for SCLC by NCCN guidelines, such as irinotecan combined with carboplatin (IC) or cisplatin (IP) (8). IC and IP regimens are commonly used in Japan (42). According to the Japan Clinical Oncology Group, patients who received IP had notably longer mOS than those who received EP (42). In a meta-analysis involving a large number of Caucasian and Asian patients with treatment-naïve EDSCLC, IP regimens were correlated to elevated response rates and improved OS compared to EP regimens (50). Meanwhile, in researches from North America, Australia, and Europe, the curative efficacy of IP and EP was confirmed to be comparable $(24,25,51)$. Therefore, when 
choosing among equally effective regimens, decisions are mainly influenced by local routine practice, medical costs, quality of life considerations, and convenience (40).

Different from NSCLC, targeted therapy showed no significant impact on SCLC at present. While typical genome of SCLC harbors substantial genomic aberrations, actionable mutations are notably absent in protein kinases. Rather, TP53 and RB1 alterations are common in SCLC; few mutations in SCLC have yielded viable drugs so far (52). Although high response rates have been provided, chemotherapy seems to have reached a plateau and SCLC is still characterized by near-inevitable and rapid recurrence (53). Adding immunotherapies to first-line chemotherapy may become an effective combination therapy and two randomized clinical trials (IMpower 133 and CASPIAN) demonstrated significant improvement of immunotherapy in SCLC $(54,55)$, which established a new standard of care. With the discovery of new drug targets and the continuous emergence of new combination treatment options, there remains several challenges including the comorbidities accompanying this smoking-correlated tumor, rapid clinical course of disease, difficulty in obtaining enough tissue samples to analyze for guiding drug design, and complications associated with the use of new drugs. Thus, a greater understanding of the underlying progression pattern and relevant biology of SCLC is required.

Some limitations exist in the present study. Firstly, this was a retrospective study. Secondly, the sample size was not large enough, and more data are needed to support our conclusions. We will further carry out a large-scale prospective research for verification in the further.

In recent years, studies on new therapeutic strategies for SCLC have made progress. Immunotherapy is now at the forefront of research and might open a new era for SCLC treatment. By suppressing certain immune checkpoints, tumor immune escape can be reversed, resulting in favorable outcomes (56). Inhibitors of programmed cell death-1 and programmed cell death ligand-1 have already been applied to treat lung cancer and other solid tumors (57). Other novel immune checkpoints such as lymphocyteactivation gene-3 (LAG-3) and inhibitory killer cell immunoglobulin-like receptor (KIRs) are likely to become promising therapeutic targets in the near future $(58,59)$. Furthermore, in future, we will also explore the influence of first-line chemotherapy on the efficacy of subsequent immunotherapy.

\section{Conclusions}

In this study, we conducted correlation and survival analyses of SCLC patients. Statistical significance was found between patient prognosis and the curative efficacy of 2-cycle platinum-based chemotherapy. Patients who responded to chemotherapy and showed a better curative response had significantly longer PFS and OS than chemotherapyinsensitive patients. Curative efficacy might be a prognostic factor of SCLC.

\section{Acknowledgments}

Funding: This study was supported in part by grants from Young Talents in Shanghai, National Natural Science Foundation of China (81802255), Young Talents in Shanghai (2019 QNBJ), 'Dream Tutor' Outstanding Young Talents Program (fkyq1901), the Clinical Research Project of Shanghai Pulmonary Hospital (fk18005), Key Discipline in 2019 (Oncology), Project of Shanghai Municipal Science and Technology Commission (Project of Municipal Science and Technology Commission), Scientific Research Project of Shanghai Pulmonary Hospital (fkcx1903), Shanghai Municipal Commission of Health and Family Planning (2017YQ050), Innovation Training Project of SITP of Tongji University, Key Projects of Leading Talent (19411950300), and the Youth Project of Hospital Management Research Fund of Shanghai Hospital Association (Q1902037).

\section{Footnote}

Reporting Checklist: The authors have completed the STROBE reporting checklist. Available at http://dx.doi. org/10.21037/jtd-21-216

Data Sharing Statement: Available at http://dx.doi. org/10.21037/jtd-21-216

Conflicts of Interest: All authors have completed the ICMJE uniform disclosure form (available at http://dx.doi. org/10.21037/jtd-21-216). The authors have no conflicts of interest to declare.

Ethical Statement: All authors are accountable for all aspects of the work in ensuring that questions related 
to the accuracy or integrity of any part of the work are appropriately investigated and resolved. All participants were competent to provide consent. Approval of this study was obtained from the ethics committee of Shanghai Pulmonary Hospital (ethics number: K20-022). All procedures performed in this study involving human participants were in accordance with the Declaration of Helsinki (as revised in 2013).

Open Access Statement: This is an Open Access article distributed in accordance with the Creative Commons Attribution-NonCommercial-NoDerivs 4.0 International License (CC BY-NC-ND 4.0), which permits the noncommercial replication and distribution of the article with the strict proviso that no changes or edits are made and the original work is properly cited (including links to both the formal publication through the relevant DOI and the license). See: https://creativecommons.org/licenses/by-nc-nd/4.0/.

\section{References}

1. Bray F, Ferlay J, Soerjomataram I, et al. Global cancer statistics 2018: GLOBOCAN estimates of incidence and mortality worldwide for 36 cancers in 185 countries. CA Cancer J Clin 2018;68:394-424.

2. Global Burden of Disease Cancer Collaboration; Fitzmaurice C, Akinyemiju TF, et al. Global, Regional, and National Cancer Incidence, Mortality, Years of Life Lost, Years Lived With Disability, and Disability-Adjusted LifeYears for 29 Cancer Groups, 1990 to 2016: A Systematic Analysis for the Global Burden of Disease Study. JAMA Oncol 2018;4:1553-68.

3. Travis WD. Advances in neuroendocrine lung tumors. Ann Oncol 2010;21 Suppl 7:vii65-71.

4. van Meerbeeck JP, Fennell DA, De Ruysscher DK. Smallcell lung cancer. Lancet 2011;378:1741-55.

5. Zakowski MF. Pathology of small cell carcinoma of the lung. Semin Oncol 2003;30:3-8.

6. Bernhardt EB, Jalal SI. Small Cell Lung Cancer. Cancer Treat Res 2016;170:301-22.

7. Gazdar AF, Bunn PA, Minna JD. Small-cell lung cancer: what we know, what we need to know and the path forward. Nat Rev Cancer 2017;17:725-37.

8. Kalemkerian GP, Loo BW, Akerley W, et al. NCCN Guidelines Insights: Small Cell Lung Cancer, Version 2.2018. J Natl Compr Canc Netw 2018;16:1171-82.

9. Thomas A, Pattanayak P, Szabo E, et al. Characteristics and Outcomes of Small Cell Lung Cancer Detected by
CT Screening. Chest 2018;154:1284-90.

10. Kuo YH, Lin ZZ, Yang YY, et al. Survival of patients with small cell lung carcinoma in Taiwan. Oncology 2012;82:19-24.

11. Zarogoulidis K, Boutsikou E, Zarogoulidis P, et al. The role of second-line chemotherapy in small cell lung cancer: a retrospective analysis. Onco Targets Ther 2013;6:1493-500.

12. Lally BE, Urbanic JJ, Blackstock AW, et al. Small cell lung cancer: Have we made any progress over the last 25 years? Oncologist 2007;12:1096-104.

13. Rudin CM, Ismaila N, Hann CL, et al. Treatment of Small-Cell Lung Cancer: American Society of Clinical Oncology Endorsement of the American College of Chest Physicians Guideline. J Clin Oncol 2015;33:4106-11.

14. Farago AF, Keane FK. Current standards for clinical management of small cell lung cancer. Transl Lung Cancer Res 2018;7:69-79.

15. Waqar SN, Morgensztern D. Treatment advances in small cell lung cancer (SCLC). Pharmacol Ther 2017;180:16-23.

16. Rudin CM, Ismaila N, Hann CL, et al. Treatment of Small-Cell Lung Cancer: American Society of Clinical Oncology Endorsement of the American College of Chest Physicians Guideline. J Clin Oncol 2015;33:4106-11.

17. Mascaux C, Paesmans M, Berghmans T, et al. A systematic review of the role of etoposide and cisplatin in the chemotherapy of small cell lung cancer with methodology assessment and meta-analysis. Lung Cancer 2000;30:23-36.

18. Pujol JL, Carestia, Daures JP. Is there a case for cisplatin in the treatment of small-cell lung cancer? A meta-analysis of randomized trials of a cisplatin-containing regimen versus a regimen without this alkylating agent. $\mathrm{Br} \mathrm{J}$ Cancer 2000;83:8-15.

19. Rossi A, Di Maio M, Chiodini P, et al. Carboplatin- or cisplatin-based chemotherapy in first-line treatment of small-cell lung cancer: the COCIS meta-analysis of individual patient data. J Clin Oncol 2012;30:1692-8.

20. He Y, Jia K, Dziadziuszko R, et al. Galectin-9 in non-small cell lung cancer. Lung Cancer 2019;136:80-5.

21. He Y, Liu S, Mattei J, et al. The combination of anti-KIR monoclonal antibodies with anti-PD-1/PD-L1 monoclonal antibodies could be a critical breakthrough in overcoming tumor immune escape in NSCLC. Drug Des Devel Ther 2018;12:981-6.

22. He Y, Rozeboom L, Rivard CJ, et al. PD-1, PD-L1 Protein Expression in Non-Small Cell Lung Cancer and Their Relationship with Tumor-Infiltrating Lymphocytes. Med Sci Monit 2017;23:1208-16.

23. Koinis F, Kotsakis A, Georgoulias V. Small cell lung cancer 
(SCLC): no treatment advances in recent years. Transl Lung Cancer Res 2016;5:39-50.

24. Hanna N, Bunn PA, Langer C, et al. Randomized phase III trial comparing irinotecan/cisplatin with etoposide/ cisplatin in patients with previously untreated extensivestage disease small-cell lung cancer. J Clin Oncol 2006;24:2038-43.

25. Lara PN, Natale R, Crowley J, et al. Phase III Trial of Irinotecan/Cisplatin Compared With Etoposide/Cisplatin in Extensive-Stage Small-Cell Lung Cancer: Clinical and Pharmacogenomic Results From SWOG S0124. J Clin Oncol 2009;27:2530-5.

26. Schwartz LH, Litiere S, de Vries E, et al. RECIST 1.1-Update and clarification: From the RECIST committee. Eur J Cancer 2016;62:132-7.

27. Cerny T, Blair V, Anderson H, et al. Pretreatment prognostic factors and scoring system in 407 small-cell lung cancer patients. Int J Cancer 1987;39:146-9.

28. Rawson NS, Peto J. An overview of prognostic factors in small cell lung cancer. A report from the Subcommittee for the Management of Lung Cancer of the United Kingdom Coordinating Committee on Cancer Research. Br J Cancer 1990;61:597-604.

29. Lee CH LC, Wang CY, Huang TC, Wu YY, Chien WC, Chen JH. . Premorbid BMI as a prognostic factor in smallcell lung cancer-a single institute experience. Oncotarget 2018;9:24642-52.

30. Owonikoko TK, Behera M, Chen ZJ, et al. A Systematic Analysis of Efficacy of Second-Line Chemotherapy in Sensitive and Refractory Small-Cell Lung Cancer. J Thorac Oncol 2012;7:866-72.

31. Alves RDS, Meurer RT, Roehe AV. MYC amplification is associated with poor survival in small cell lung cancer: a chromogenic in situ hybridization study. J Cancer Res Clin Oncol 2014;140:2021-5.

32. Chen S, Wu S, Zhang L, et al. CD39: the potential target in small cell lung cancer. Transl Lung Cancer Res 2020;9:1483-95.

33. Sun C, Zhang L, Zhang W, et al. Expression of PD-1 and PD-L1 on Tumor-Infiltrating Lymphocytes Predicts Prognosis in Patients with Small-Cell Lung Cancer. Onco Targets Ther 2020;13:6475-83.

34. Igawa S, Naoki K, Shintani Y, et al. Survival and prognostic factors in elderly patients receiving second-line chemotherapy for relapsed small-cell lung cancer: Results from the Japanese Joint Committee of Lung Cancer Registry. Lung Cancer 2020;146:160-4.

35. Ardizzoni A, Hansen H, Dombernowsky P, et al.
Topotecan, a new active drug in the second-line treatment of small-cell lung cancer: a phase II study in patients with refractory and sensitive disease. The European Organization for Research and Treatment of Cancer Early Clinical Studies Group and New Drug Development Office, and the Lung Cancer Cooperative Group. J Clin Oncol 1997;15:2090-6.

36. Rottenberg S, Disler C, Perego P. The rediscovery of platinum-based cancer therapy. Nat Rev Cancer 2021;21:37-50.

37. Todd RC, Lippard SJ. Inhibition of transcription by platinum antitumor compounds. Metallomics 2009;1:280-91.

38. Green RA, Humphrey E, Close H, et al. Alkylating agents in bronchogenic carcinoma. Am J Med 1969;46:516-25.

39. Alvarez MP, Rubio OG, Cosp XB, et al. Chemotherapy versus best supportive care for extensive small cell lung cancer. Chemotherapy versus best supportive care for extensive small cell lung cancer. Cochrane Database Syst Rev 2009;(4):CD001990.

40. Sambrook RJ, Girling DJ. A national survey of the chemotherapy regimens used to treat small cell lung cancer (SCLC) in the United Kingdom. Br J Cancer 2001;84:1447-52.

41. Douple EB CC, Curphey TJ, et al. Evaluation of drug efficacy in vitro using human small cell carcinoma of the lung spheroids. Cancer 1985;56:1918-25.

42. Sundstrom S, Bremnes RM, Kaasa S, et al. Cisplatin and etoposide regimen is superior to cyclophosphamide, epirubicin, and vincristine regimen in small-cell lung cancer: Results from a randomized phase III trial with 5 years' follow-up. J Clin Oncol 2002;20:4665-72.

43. Fruh M, De Ruysscher D, Popat S, et al. Small-cell lung cancer (SCLC): ESMO Clinical Practice Guidelines for diagnosis, treatment and follow-up. Ann Oncol 2013;24:99-105.

44. Brock MV, Hooker CM, Syphard JE, et al. Surgical resection of limited disease small cell lung cancer in the new era of platinum chemotherapy: Its time has come. J Thorac Cardiovasc Surg 2005;129:64-72.

45. Hatfield LA, Huskamp HA, Lamont EB. Survival and Toxicity After Cisplatin Plus Etoposide Versus Carboplatin Plus Etoposide for Extensive-Stage Small-Cell Lung Cancer in Elderly Patients. J Oncol Pract 2016;12:666-73.

46. Jiang L, Yang KH, Guan QL, et al. Cisplatin plus etoposide versus other platin-based regimens for patients with extensive small-cell lung cancer: a systematic review and meta-analysis of randomised, controlled trials. Intern Med J 2012;42:1297-309. 
47. Govindan R, Wang X, Baggstrom MQ, et al. A phase II study of carboplatin, etoposide, and exisulind in patients with extensive small cell lung cancer: CALGB 30104. J Thorac Oncol 2009;4:220-6.

48. Rowland KM, Loprinzi CL, Shaw EG, et al. Randomized double-blind placebo-controlled trial of cisplatin and etoposide plus megestrol acetate placebo in extensive-stage small-cell lung cancer: A North Central cancer treatment group study. J Clin Oncol 1996;14:135-41.

49. Rudin CM, Salgia R, Wang XF, et al. Randomized phase II study of carboplatin and etoposide with or without the bcl-2 antisense oligonucleotide oblimersen for extensivestage small-cell lung cancer: CALGB 30103. J Clin Oncol 2008;26:870-6.

50. Jiang J, Liang X, Zhou X, et al. A meta-analysis of randomized controlled trials comparing irinotecan/ platinum with etoposide/platinum in patients with previously untreated extensive-stage small cell lung cancer. J Thorac Oncol 2010;5:867-73.

51. Schmittel A, von Weikersthal LF, Sebastian M, et al. A randomized phase II trial of irinotecan plus carboplatin versus etoposide plus carboplatin treatment in patients with extended disease small-cell lung cancer. Ann Oncol 2006;17:663-7.

52. George J, Lim JS, Jang SJ, et al. Comprehensive genomic profiles of small cell lung cancer. Nature 2015;524:47-53.

Cite this article as: Zhu K, Jiang M, Xu Y, Chen P, Wang H, Yu J, Zhu J, Zhao W, Meng D, He Y. Curative efficacy might be an early predictor of prognosis in patients with small cell lung cancer treated with 2 cycles of platinum-based first-line chemotherapy. J Thorac Dis 2021;13(2):1205-1214. doi: 10.21037/ jtd-21-216
53. Armstrong SA, Liu SV. Immune Checkpoint Inhibitors in Small Cell Lung Cancer: A Partially Realized Potential. Adv Ther 2019;36:1826-32.

54. Horn L, Mansfield AS, Szczesna A, et al. First-Line Atezolizumab plus Chemotherapy in Extensive-Stage Small-Cell Lung Cancer. N Engl J Med 2018;379:2220-9.

55. Paz-Ares L, Dvorkin M, Chen Y, et al. Durvalumab plus platinum-etoposide versus platinum-etoposide in firstline treatment of extensive-stage small-cell lung cancer (CASPIAN): a randomised, controlled, open-label, phase 3 trial. Lancet 2019;394:1929-39.

56. Leone P, De Re V, Vacca A, et al. Cancer treatment and the KIR-HLA system: an overview. Clin Exp Med 2017;17:419-29.

57. He Y, Yu H, Rozeboom L, et al. LAG-3 Protein Expression in Non-Small Cell Lung Cancer and Its Relationship with PD-1/PD-L1 and Tumor-Infiltrating Lymphocytes. J Thorac Oncol 2017;12:814-23.

58. He Y, Bunn PA, Zhou C, et al. KIR 2D (L1, L3, L4, S4) and KIR 3DL1 protein expression in non-small cell lung cancer. Oncotarget 2016;7:82104-11.

59. He Y, Rivard CJ, Rozeboom L, et al. Lymphocyteactivation gene-3, an important immune checkpoint in cancer. Cancer Sci 2016;107:1193-7.

(English Language Editor: J. Reynolds) 